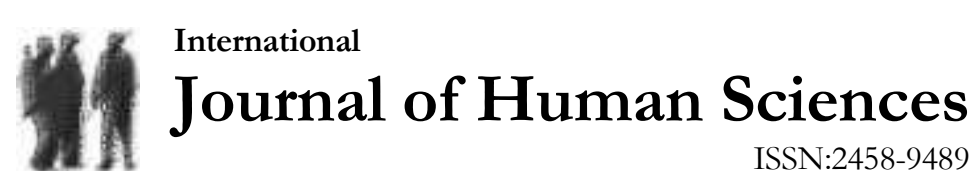

Volume 16 Issue 4 Year: 2019

\section{Rational emotive behavior therapy from a new perspective}

\author{
Ekrem Sedat Şahin ${ }^{1}$ \\ Nilüfer Voltan Acar ${ }^{2}$
}

\begin{abstract}
The aim of this study is to give a different dimension to the Rational Emotional Behavioral Therapy (REBT) Approach. For this purpose, by using the induction method; Growth has been reached. By adding $G$ to the ABCDEF process at the end of the study; a final dimension. Theory and applications of REBT relies on the A-B-C model. According to this model, A (Activating Event) is a phenomenon or the existence of an event or a person's behavior. In other words, A is the activating event. According to the A-B-C model, C (emotive or behavioral consequence) is the individual's emotive or behavioral reaction or consequence that follows it. A (the actual event) does not cause C. what plays the primary role in the formation of $\mathrm{C}$ is the persons belief about $\mathrm{A}$, and that is $\mathrm{B}$.

$\mathrm{A}-\mathrm{B}$ and $\mathrm{C}$ comes $\mathrm{D}$ (disputing). $\mathrm{D}$ is the questioning of irrational and dysfunctional beliefs. Although REBT makes use of some other cognitive, emotive, and behavioral components in order to help reduce irrational beliefs of clients to a minimum, it emphasizes this disputing process (D) both during therapy and in daily life. Clients eventually reach E, namely, effective behavior or life philosophy, which has a practical side. $\mathrm{E}$ (effects) provides the effects of cognitively re-thinking in a more rational behavior mode.

In an interview conducted with Ellis in 2005, Ellis suggested $\mathrm{F}$ which forces people to obey new rational beliefs in order to strengthen $\mathrm{E}$, which has an influence on dispute. It can be said that $\mathrm{F}$ is basically Functional Feeling and Behavior which ensures the continuity of rational beliefs that come out as a result of $\mathrm{E}$ (effect) and which makes it easier to evaluate events within their own reality by following these rational beliefs.

When REBT is considered with a new perspective, $G$ (growth) can be added to the process after $\mathrm{F}$ (functional feeling and behavior), because it takes some time for the rational beliefs formed with the influence of $\mathrm{F}$ to set in for the individual.

In a psychological counseling which applies a rational emotive behavior approach, the aim is to break this negative spiral. Irrational beliefs (B) of the individual are refuted by disputing them (D). In the new case which came about with the effect $(\mathrm{E})$ of this dispute, functional emotions and behaviors (F) occur. One of the aims in REBT-based psychological counseling is for the client to realize his or her irrational beliefs, distinguish them from rational ones, and to learn to overcome irrational beliefs. The client learning this process and using rational beliefs in the face of new events can be called growth $(G)$. In this respect, the main aim of REBT-based psychological counseling can be said to be enabling growth.
\end{abstract}

Keywords: REBT, A-B-C personality theory, relationship between the components A-B-C-D-E-F, G (Growth).

\footnotetext{
${ }^{1}$ Dr., ekremsedat33@gmail.com

2 Prof. Dr., TED Universty, Faculty of Education, Department of Educational Sciences - Guidance and Psychological Counseling, Ankara, Turkey, nilufer.voltan@tedu.edu.tr
} 


\section{Introduction}

Rational Emotive Behavior Therapy (REBT) was developed by clinical psychologist Albert Ellis in 1950s (Sharf, 2014). The basic assumption of REBT is that people's way of interpreting events and their experience determine the formation of the psychological difficulties they face. REBT is based on the premise that thoughts, emotions, and behaviors influence one another to a great extent and that they have a reciprocal cause and effect relationship (Corey, 2008). In other words, in REBT a person's thoughts, emotions, and behaviors are considered as a whole because according to the basic assumption of REBT, the way an individual evaluates or views an event is influenced by their state of mind and in return may determine in what kind of emotional state that person will be in.

When developing REBT, Ellis was influenced by the Roman philosopher Epictetus, who argued that "people are not only influenced by situations but also by how they view those situations" (Sharf, 2014).Ellis (2010) indicates that how people make themselves uncomfortable is more important than the actions they actualized; he says that "people make themselves uncomfortable with the things that happen to them, with their thoughts, emotions, and actions". When one client says "someone made me feel like this" the well-known response by Ellis is as follows: "this is really impossible, no one can make you feel something unless they hold a baseball bat in their hands" (Ellis, 2002). In brief, what affects the individual in a given situation is his or her perception of it and the thought, emotion, and behavior components he or she developed in relation to this perception, and not the actual situation itself. These components can influence the individual singularly or holistically.

Ellis (1998) considers his theory a structuralist one. What he tries to underline with this is as follows: people create their own reality themselves, and the most critical factor determining what the behavior of the individual will be is what his perception of reality is, and not the reality interpreted by the outside. Reality interpreted by the outsiders may not be the same with the reality of the individual. In other words, something that affects the individual immensely may not be as effective for others. At the basis, lies the fact that the perception of reality of the individual is different from the perception of reality of others.

\section{How Rational Emotive Behavior Approach Views the Human Being}

According to Rational Emotive Behavior Therapy (REBT), people are responsible for their own behavior. They can easily decide whether a behavior is "good" or "bad," whether a behavior harms or benefits them and the society (Ellis, 1994). In this respect, according to REBT, it can be said that people are active beings capable of taking responsibility of their own behavior, and that the main responsibility falls onto them rather than on their environment or other people.

Rational Emotive Behavior Therapy (REBT) looks at human nature rather neutrally. REBT contends that in actuality human beings have some good and some bad within themselves (Murdock, 2013). REBT also assumes that the individual has the potential of both rational and irrational or faulty thinking (Corey, 2008). According to Ellis (2008), this dichotomy is biologically manifested in human nature and it is maintained unless a new thinking style is learned. One part of this dichotomy, that is, rationality, denotes the attempt to succeed in one's values and aims through effective, flexible, logical, and scientific methods (Ellis, 1962) and the other part of the dichotomy, that is, irrationality, or as Ellis defines it, irrational Beliefs (iBs) denotes the realization of disturbing thoughts (Gladding, 2013) .

In short, according to REBT, people are beings who are capable of rational and irrational thinking. There may be times when people do not or cannot use their rational thinking skills. Then, they can be disturbed since they approach things irrationally or since they cannot evaluate the situation rationally.

Ellis argues that human beings should be long-term hedonists. By "being Hedonist" he meant a basic motivation as avoiding pain and looking for pleasure (Murdock, 2013). This 
situation, which is defined as responsible hedonism (Sharf, 2014), emphasizes the persistence of long-term satisfaction by avoiding short-term pleasures (Dryden and Ellis, 2001). For instance, a teenager who could make money through day wage work chooses instead to study hard and graduate from a university because he or she wants to have a financially and socially more permanent and secure job in the future; as this scenario shows, if an individual strives for a longterm pleasure instead of pursuing a short-term one, they would be more happy.

Practitioners of Rational Emotive Behavior Therapy (REBT) see human beings as important organizms because human beings are holistic and aim-oriented (Dryden, 1990). Ellis (2004) believes that preferably people should accept themselves as they are. People should accept the fact that they can make mistakes and that they are valuable, because their qualities and assets are stronger than what people themselves or others think of these assets. In other words, the individual or other people may not see the assets in the individual because perception comes into play here. However, judgement based on perception may not be the same with reality. It can be said that the actual situation of the individual is better than what he or she perceives, and thus unconditional self-acceptance is an appropriate behavior.

Rational Emotive Behavior Therapy (REBT) sees people as important, holistic, and target-oriented organizms (Ellis, 1986). Although REBT sees people as target-oriented creatures, it also accepts that they have irrational sides. In this respect, whether rational or not, the root of most of the beliefs and internal conversations of people are mostly go to their childhood years. These beliefs are learned from parents, family members, social circle, and especially from mass media (Clark, 2000). Thus, at the root of rational as well as irrational beliefs lie childhood experiences, movies during childhood, fairy tales or stories listened to or read at that time, friendships formed, and games played during childhood; in short environment can be said to be influential.

According to Rational Emotive Behavior Therapy (REBT), interpersonal relationships within family, circle of friends, school and other social groups have a significant effect on the expectations of the individual for themselves as well as others (Sharf, 2014). According to REBT, the environment plays an important role in the formation of belief systems. These beliefs are learned from parents, family members, social circle, and especially from mass media (Clark, 2000). As mentioned above, it can be said that in addition to people's biological inclinations, their environment and experience have an effect at the basis of beliefs.

Ellis (1987) was influenced by the power of biological factors in the formation of human identity. He indicated that the individual has the tendency to self-harm and think in irrational ways. Ellis believes that all people may have basic irrationalities, and that this is independent of culture or level of education (Nelson-Jones, 2003). Ellis (1987) also indicates that although environmental factors influence events, when people have certain innate inclinations which cause them to react in a certain way by harming themselves and others when they cannot get what they want. In short, according to REBT, it can be said that biology has an important role in the formation and development of irrational beliefs which cause the individual psychological problems. It is seen that social and biological factors that affect the psychology of the individual are also underlined in the basic assumptions of REBT.

\section{Basic Assumptions of Rational Emotive Behavior Therapy (REBT)}

In order to understand Rational Emotive Behavior Therapy, its basic assumptions should be known. Below are given the basic assumptions of REBT (Corey, 2008):

1. Thought, emotions, and behaviors are in constant interaction, and they influence one another.

2. Emotional disturbances come out in a complex way with the effect of environmental and biological factors.

3. People are responsible for their own cognitive, emotive, and behavioral disturbances.

4. When people experience unfortunate events, they tend to develop irrational beliefs which are considered to be dogmatic and constant. 
5. What leads to emotional collapse is not the unfortunate events themselves but the individual's irrational beliefs related to these events.

6. Many people have an extraordinary tendency to bring themselves to emotional collapse. Thus, people find it almost impossible to keep sane.

7. People have the capacity to realize how their beliefs affect them negatively. When they realize this, they will have the power to discuss their irrational beliefs and exchange them with rational ones. With the change of these beliefs, people can also change their unhealthy emotions and disruptive behavior.

8. Irrational beliefs can be destroyed by a combination of cognitive, emotive, and behavioral methods.

9. Clients should be willing to change. This is an indispensable and compulsory thing for change to take place.

REBT's basic assumptions rely on the view that thoughts, emotions, and behaviors are in constant interaction. According to this view, individuals are responsible for their behavioral disturbance. In this respect, the individual should be willing to change and to receive treatment, and they should work on it (Gençtanırım and Voltan-Acar, 2007). The individual has the power to recognize irrational beliefs. They can overcome these irrational beliefs with this power.

According to REBT, rational beliefs help people reach their aims, and make them more amiable by regulating emotions (Bernard, Ellis and Terjesen, 2006) There are four types of rational belief, namely, flexibility in preferences, high tolerance for frustration, being against turning things into catastrophe, and acceptance (Dryden and Neenan, 2006). In short, rational beliefs are flexible in nature and they do not restrict the individual within strict limits. Rational beliefs enable an individual to bear difficulties. People can accept what they experience without viewing them as catastrophic. In other words, rational beliefs can support an individual in maintaining a healthy psyche.

According to Rational Emotive Behavior Therapy (REBT), irrational beliefs are rigid, and they include demands and absolute musts (Bernard, Ellis and Terjesen, 2006). Moreover, they also include orders and desires (Nelson-Jones, 2003). At the root of irrational beliefs lie a sense of guilt, obligations, and imperatives (Corey, 2008; Sharf, 2014). According to Ellis (1994), irrational beliefs can be thought of in three categories, namely:

1. A person's self-impositions: I myself must, under each and every circumstance, always do the best, and must gain the respect of people who are important to me. If I fail in this important - and sacred! - endeavor, this is a horrible thing. It means I am a bad, inadequate, and worthless person. It means that I will always be a failure and that I deserve to suffer.

2. Impositions on other people: You, the important people, with whom I am in contact, you must always be kind, thoughtful and fair towards me under each and every circumstance; otherwise, it is a really bad thing and that means you deserve to be punished for treating me as such.

3. Impositions about life: This life I lead, ecological, environmental, economic and political conditions must be reasonable, safe, easy, and fun under each and every circumstance. If not, my life becomes unbearable.

In short, irrational beliefs force the individual to reach for unreachable conditions. It can be said that the above-mentioned conditions are impossible to attain. The individual in the grip of these irrational beliefs may struggle to attain them, but may also face such emotions as inadequacy, worthlessness, and guilt. These emotions and the unwanted conditions may cause him or her to be even more stuck in these irrational beliefs. Then the individual would interpret the events with the intense influence of these beliefs that he/she is stuck in. It can be said that at the basis of this interpretation also lies the compelling characteristics of the individual. 
Şahin, E. S., \& Voltan Acar, N. (2019). Rational emotive behavior therapy from a new perspective. Journal of Human Sciences, 16(4), 894-906. doi:10.14687/jhs.v16i4.5821

\section{Characteristics of Irrational Beliefs}

When literature is examined, it can be seen that irrational beliefs have different characteristics. Below is some information about the generally accepted characteristics of irrational beliefs.

Being demanding: These demands may be about the individual, others, or the environment. They may be explicit or implicit, but they almost always contain such expressions as "must" and "should" (Nelson-Jones, 2003). For instance, the following sentences express irrational beliefs: "I must be very accomplished in every field," "others should respect me," and "everyone should love me."

Overgeneralization: Overgeneralization is expanding one single instance into covering a whole situation, such as moving from one observation like "I failed in the test" to thinking "I will always fail; I don't have enough to be successful" (Nelson-Jones, 2003). In other words, overgeneralization refers to an individual's extension of negativity about something to new things he/she would face in the future.

Self-grading: Another type of overgeneralization is self-grading. While living by evaluating one's characteristics is functional, grading one's worth is irrational and not functional. The most philosophical solution to the question of self-worth is to really accept one's self rather than grading (Ellis, 1973). People should strive to accept themselves unconditionally, otherwise they would blame themselves for being "worthless" or "bad" (Ellis, 2001). This sense of worthlessness can be taken as a sign of the individual's self-grading and his or her inability to accept himself/ herself unconditionally, because worthlessness is a grade as well. It can be said that the sense of worthlessness is a low or bad grade that inhibits the individual from accepting himself or herself unconditionally.

Making it worse: Making it worse accompanies being demanding; and it increases emotiveness which inhibits the capacity for rational problem solving. Making it worse stops the individual from perceiving the initial event properly, and it blocks change (Nelson-Jones, 2003). When the individual makes it worse, he or she may not be able to evaluate it within its own reality and see the necessary and correct solutions.

Ascription mistakes: Ascription mistake denotes ascribing the reasons of one's or others' behavior to external events or internal physical situations (Ellis, 1977). At the root of ascription mistakes lie the individual's irrational beliefs.

Being against data: Being against data refers to the inability to test and refute the irrational belief (Nelson-Jones, 2003). No matter how much you try to express that the individual's irrational belief is dysfunctional and harmful, he or she does not take this data into consideration. Thus, the irrational belief continues to exist.

Irrational beliefs which are seen to be the basic reason of psychological disorder consist of rigid, dogmatic, unhealthy, discordant demands and hence are also called "demanding beliefs" (Ellis, 2000). Irrational beliefs are thoughts that appear on their own, they are part of the mental process, and are also thought that are frequently unnoticed (Türkçapar, 2011).

It can be said that irrational beliefs are rooted and resistant. Compulsions existent in irrational beliefs may inhibit the individual. According to Harrington (2005), people with low inhibition tolerance are more likely to be disturbed compared to those who have high inhibition tolerance. Once someone has an irrational belief, this belief tends to occur recurrently. In this respect, it can be claimed that it is highly difficult for someone with low inhibition tolerance to deal with irrational beliefs or to completely overcome it.

Lowness of inhibition tolerance is related to anxiety (Sharf, 2014). According to Ellis (2003) there are two types of anxiety. These are discomfort anxiety and ego anxiety. In the discomfort, there is a threat to the individual's level of comfort. In ego anxiety, on the other hand, the threat is on the individual's sense of self-esteem. In both discomfort anxiety and ego anxiety, individuals believe that the result will be terrible or catastrophic when they cannot get or do what they want to get or do. Such strongly experienced negative emotions cause the individual 
Şahin, E. S., \& Voltan Acar, N. (2019). Rational emotive behavior therapy from a new perspective. Journal of Human Sciences, 16(4), 894-906. doi:10.14687/jhs.v16i4.5821

to perceive them as real. Negative emotions use a cyclic reasoning (Ellis, 1994). In other words, negative emotions cause both the formation of anxiety and maintain their existence as a result of this anxiety. This process can be better understood with the A-B-C personality theory.

\section{Rational Emotive Behavior A-B-C Theory of Self}

Theory and applications of Rational Emotive Behavior Therapy (REBT) relies on the AB-C model. According to this model which puts forth the primary source of emotions, psychological breakdown is not caused by the actual event but by the thoughts and inner dialogues of the individual related to this event and situations (Gençtanırım and Voltan-Acar, 2007). According to this model, A (Activating Event) is a phenomenon or the existence of an event or a person's behavior (Corey, 2008). In other words, A is the activating event (NelsonJones, 2003). A can be supported or prevented aims (Sharf, 2014). In other words, A can be positive or negative events and situations that can be experienced, and it can also be living or inanimate beings.

According to the A-B-C model, C (emotive or behavioral consequence) is the individual's emotive or behavioral reaction or consequence that follows it. Reaction can be healthy or unhealthy (Corey, 2008). Cs can be emotional experiences (such as sadness, unhappiness, anxiety, and depression) or behaviors (such as being persistent to do something, and doing something repeatedly) (Murdock, 2013). A, does not cause C. what plays the primary role in the formation of $C$ is the persons belief about $A$, and that is B (Corey, 2008). In other words, what determines C's content is not the actual content of A but the new content created about the A by the person who experiences $\mathrm{A}$.

According to the A-B-C model, A reacts, consciously or unconsciously, through belief systems B (Sharf, 2014). B consists of a person's beliefs about A and their verbal expressions of them (Nelson-Jones, 2003). Rational beliefs lead to functional consequences (C); irrational beliefs lead to dysfunctional consequences (C) (Szentagotai and Kallay, 2006). The relationship between the A-B-C components was expressed by Corey (2008) as follows:

\section{$\underline{\mathbf{A}}(\underline{\mathbf{A} c t i v a t i n g}$ Event $) \quad \underline{\mathbf{B}}$ (㞷lief $) \longrightarrow \underline{\mathbf{C}}(\underline{\text { Consequence }})$}

Figure 1. Relationship between the A-B-C Components

When the relationship between the A-B-C components is examined, it can be seen that the individual ascribe a meaning to an event (A) through personal beliefs (B). Then, the individual experiences emotive or behavioral consequences depending on the meaning he or she ascribed to that event.

A-B-C Personality theory works for many people, and if the activating event is a positive one it escapes from attention. However, if the activating event is not positive various different beliefs and consequences occur. This consequence may be experienced as a positive feeling. If the activating event is not experienced in consistence with the individual's belief system (B), then the individual gives an irrational reaction to the beliefs (Sharf, 2014). According to Ellis (1994), A activates $\mathrm{B}$, and then $\mathrm{B}$ causes $\mathrm{C}$ or $\mathrm{A} \times \mathrm{B}=\mathrm{C}$. Thus, the quality of an individual's beliefs (rational or irrational) and their intensity can determine the quality (positive or negative) and intensity of that person's emotions and behavior.

To exemplify the A-B-C model, one can have a look at a student who has an increased exam anxiety upon seeing the exam paper and then failing the exam. For this student, seeing the exam paper is A. Such thoughts as "I will fail again" "I won't to be successful but I must be successful" are B. Emotional consequences as having anxiety during the exam or behavioral consequences such as shaky hands, dry mouth, and being unable to use time wisely are $\mathrm{C}$. In this example, it is seen that irrational beliefs lead to dysfunctional consequences. However, in this 
case,) if the student thinks in a rational way (B) when they see their exam paper (A) it can be said that the behavioral consequence $(\mathrm{C})$ will be more functional.

Although the A-B-C Personality theory seems simple, Ellis reveals many interactions between A, B, and C. Activating events, beliefs, and consequences all have emotive, behavioral, and cognitive components. Moreover, each of them (A, B, and C) influence and interact with one another (Sharf, 2014). In this respect, the relationship between the A-B-C components can be expressed as follows:

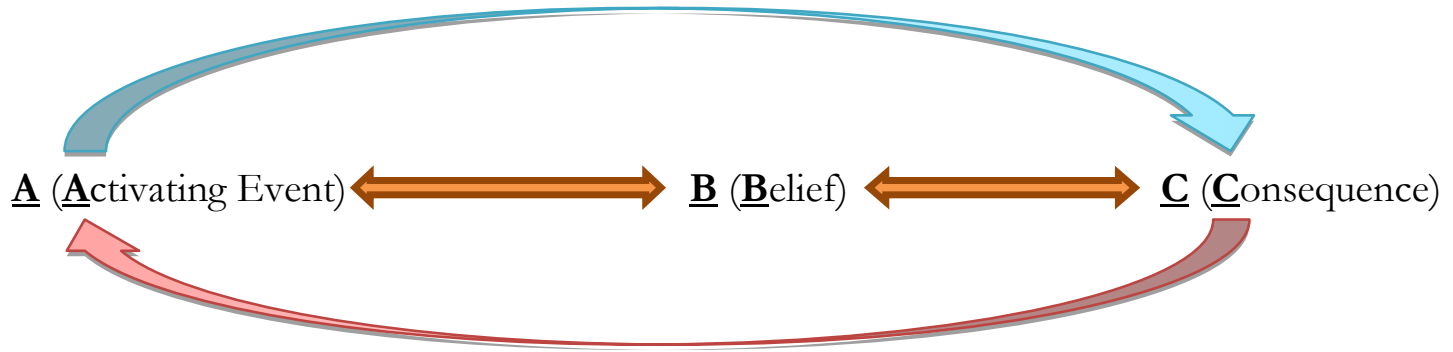

Figure 2. The reciprocal relationship between A-B-C Components

When Figure 2 is examined in the light of the above-given information, it can be said that $\mathrm{A}, \mathrm{B}$, and $\mathrm{C}$ have a reciprocal rather than a one-directional relationship. In other words, the emotional state one is in can influence the way he or she views an event. In other words, the event (A) may be interpreted with the influence of one's emotional state, and then emotional or behavioral consequences may occur due to this interpretation.

For instance, a woman, who has a normal functioning relationship with her husband, feels sorrowful because of her sister's separation from her husband. Under the influence of this, she starts to interpret behaviors she has not considered to be problems before as threats of separation, and she thinks she will also separate from her husband. In this case, she experiences separation and abandonment anxiety; this anxiety is an example of emotional state $(C)$ influencing beliefs (B) and thus the event (A) being interpreted via irrational beliefs.

In Rational Emotive Behavior Therapy (REBT), although the A-B-C frame is sufficient, there has been a necessity to enlarge it as A-B-C-D-E in terms of psychological applications (Nelson-Jones, 2003). This enlargement can be achieved in therapy.

\section{A-B-C-D-E Therapeutic Approach}

The basis of Rational Emotive Behavior Therapy (REBT) is the application of A-B-C philosophy to client problems (Sharf, 2014). After A-B and C comes D (disputing) (Corey, 2008). $\mathrm{D}$ is the questioning of irrational and dysfunctional beliefs (Popa and Bochis, 2012). If all beliefs of the individual are determined to be irrational, the aim of the rational emotive behavior therapy is to restructure these beliefs (David, Matu, Pintea, Cotet, and Nagy, 2014). According to Ellis (2003), in therapy the A-B-C philosophy is taught to clients, and then irrational beliefs are disputed.

Dispute (D) has three sections: determining the irrational belief, differentiation, and disputing the irrational beliefs (Sharf, 2014). Clients first learn to identify their irrational beliefs, especially their absolute musts, their "self-destructive" beliefs and thoughts (Corey, 2008). Next step is to differentiate rational beliefs and irrational beliefs. Being aware of obligation, necessity, pressure, and other irrational demands helps the client to learn which beliefs are rational and which beliefs are irrational. The important point in REBT is to discuss irrational beliefs. Discussing irrational beliefs help clients transform their irrational beliefs to rational ones thereby reducing their emotional distress (Sharf, 2014).

In brief, during D (disputing) B (beliefs) are handled in REBT. Here the aim of the counselor is to help the client to identify his or her irrational beliefs. Then these beliefs are differentiated from rational ones. If the client cannot differentiate irrational beliefs from rational 
one, then during counseling rational beliefs may also be disputed along with the irrational ones that the session aims to refute through disputing. This disputing may harm the client instead of helping him or her. Thus, it can be said that proper differentiation is important. In the next step, identified and differentiated irrational beliefs are refuted by dispute. The aim of this refutation can be said to develop effective and new rational beliefs in the individual.

Although Rational Emotive Behavior Theory makes use of some other cognitive, emotive, and behavioral components in order to help reduce irrational beliefs of clients to a minimum, it emphasizes this disputing process (D) both during therapy and in daily life. Clients eventually reach E, namely, effective behavior or life philosophy, which has a practical side (Corey, 2008). E (effects) provides the effects of cognitively re-thinking in a more rational behavior mode (Popa and Bochis, 2012). This philosophy, which is also behind the A-B-C model, enables individual to develop rational thoughts in order to re-think their irrational thoughts. This new and effective philosophy can bring out more effective behaviors. It can minimize feelings of depression and self-loathing, and can create satisfactory feelings (Sharf, 2014). In other words, due to the effect (E) that occurs after irrational beliefs (B) are refuted by disputing (D), individual's viewpoint can change.

In an interview conducted with Ellis in 2005, Ellis suggested F which forces people to obey new rational beliefs in order to strengthen $\mathrm{E}$, which has an influence on dispute (Bernard, 2009). It can be seen that $F$ has been used to denote different concepts in different sources (Zhaleh, Zarbakhsh and Faramarzi, 2014; David et al, 2014). While Corey (2008) uses F to mean New Feeling, Zhaleh, Zarbakhsh and Faramarzi (2014) utilize it to denote Feeling. However, David et al (2014) call F Functional Consequence. Thus, although there are different denotative meanings of F, it can be said that F is basically Functional Feeling and Behavior which ensures the continuity of rational beliefs that come out as a result of $E$ (effect) and which makes it easier to evaluate events within their own reality by following these rational beliefs. In other words, $\mathrm{F}$ (functional feelings and behaviors) can enable the individual to have a look at and evaluate new events (a new A) with a more rational philosophy. Corey (2008) expresses the relationship between A-B-C-D-E-F, which has been covered up until now, as follows:

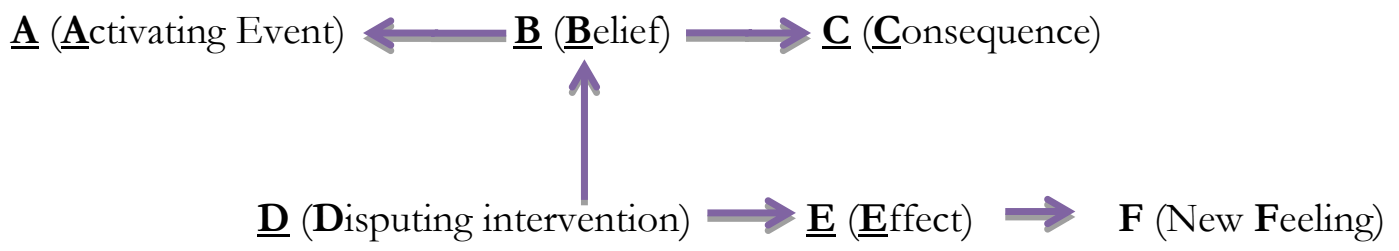

Figure 3. The Relationship between the A-B-C-D-E-F Components

According to the relationship process between A-B-C-D-E-F expressed above, an individual's beliefs (B) that he or she develops for an event (A) cause emotions and behaviors (C). If these beliefs are not rational, they are refuted by disputing them (D). With the effect formed by the dispute, new emotions and behaviors come out. In order to ensure the strengthening and continuation of these emotions and behaviors functional feelings and behaviors $(\mathrm{F})$ are used.

According to Ellis (1999), when an individual has a saddening ABC experience, he or she sees the experiences that prompt $\mathrm{C}$ as $\mathrm{A} 2$ and then put this on $\mathrm{B}$. Ellis calls such disorders secondary disorders. This comes out as a reaction to the first $\mathrm{ABC}$ sequencing. In other words, the individual puts the case in a wrong direction by trusting his or her irrational belief as a reaction to A1. As such, the individual experiences more problems as he or she adds an irrational belief to A2 (Sharf, 2014). In this respect, it can be said that secondary disorders stem from the first $\mathrm{ABC}$ experience. In this case, the $\mathrm{D}$ in psychological counseling is to prevent secondary disorders and to break the negative spiral as well. As mentioned above, the spiral can get gradually bigger and more disturbing if it is not broken. 
For instance a person fired from his or her job may evaluate this as follows. Being fired is A1. Such thoughts as "I am incompetent in everything, I can never be successful" are B. Senses of low self-esteem and self-blame as well as depressive behavior are C. These feelings and behaviors may affect negatively the fired person's job applications (A2). Under the influence of such feelings, that person may feel a more intense low self-esteem and self-blame, there may be increase in his or her depression. Thus, during psychological counseling irrational beliefs (B) which evaluate A1 are tried to be disputed so as to break the negative spiral. Taking into consideration the relationship between A-B-C, this case can be expressed with the following figure.

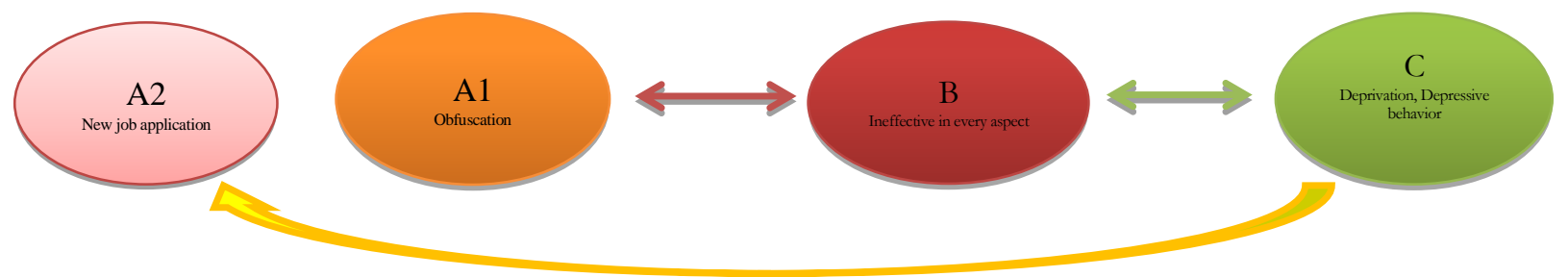

Figure 4. The formation of secondary disorders

The process in which A2 can be rationally evaluated is when $\mathrm{C}$ is positive feelings and behaviors. In addition to this, when an irrational belief (B) is disputed in a discussion (D) during psychological counseling, A2 can be rationally evaluated because new rational beliefs can bring out functional feelings (F) such as "I can find a new job even if I am fired" and behaviors such as "looking for a new job" as a result of the effect (E) of this dispute. As mentioned above, there is a similarity between positive $\mathrm{C}$ and $\mathrm{F}$. This process can be illustrated as follows:

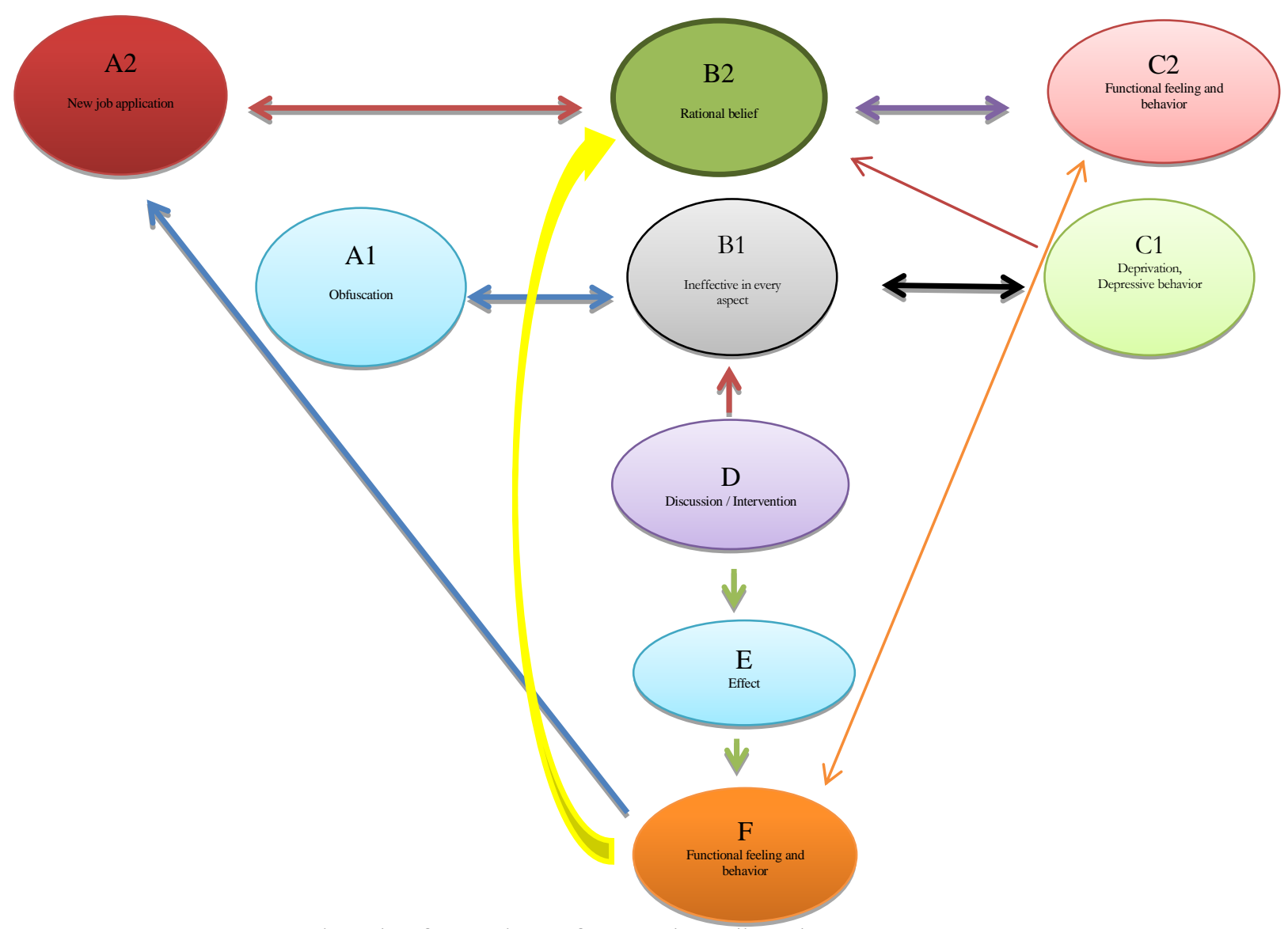

Figure 5. Preventing the formation of secondary disorders 
Şahin, E. S., \& Voltan Acar, N. (2019). Rational emotive behavior therapy from a new perspective. Journal of Human Sciences, 16(4), 894-906. doi:10.14687/jhs.v16i4.5821

In Figure 5, how secondary disorders can be prevented was tried to be expressed with a new perspective. Irrational beliefs which cause negative feelings and behaviors in the individual (B1) is reputed with dispute (D) and functional feelings and behaviors (F) come out as a result of the new effect (E). Functional feelings and behaviors can affect the occurrence of a new experience, as can be seen in the example of applying for a new job. On the other hand, it can also affect the individual's evaluation of a new experience. In other words, it allows the individual to deal with and evaluate A2 with a more rational belief (B2) formed with the influence of F instead of with an irrational belief formed with the influence of $\mathrm{C} 1$. In this way, the individual can experience positive feelings and behaviors (C2). In this case, $\mathrm{C} 1$ cannot influence A2 because $\mathrm{C} 1$ becomes dysfunctional after the refutation of B1.

When Rational Emotive Behavior Therapy (REBT) is considered with a new perspective, $\mathrm{G}$ (growth) can be added to the process after $\mathrm{F}$ (functional feeling and behavior), because it takes some time for the rational beliefs formed with the influence of $\mathrm{F}$ to set in for the individual. According to Ellis (2002), it is not enough to be aware of the irrational beliefs. It is significant to actively deal with irrational beliefs and to develop rational ones by using the info coming from AB- C personality theory. In this respect, development rational beliefs and their becoming permanent can be called Growth.

According to Ellis (2003), an important and common approach in REBT is to teach the A-B-C philosophy to clients (cited in Sharf, 2014). In REBT, individuals are offered a philosophical change with which they can protect themselves from discomforting irrational beliefs and repeated disorders (Ellis, 2008). During the REBT process, individuals are shown how to achieve what they want in a more rational way (Sharf, 2014). It can be said that these individuals show Growth and that they will evaluate new events, in other words As, with the rational beliefs that come out as a result of this growth.

A young man abandoned by her girlfriend, for instance, may think that he is lacking and that no one will love him no matter what he does (B1). He may experience depression due to these thoughts, and he may refrain from having a new girlfriend (C2). REBT makes this young man be aware of his irrational beliefs and refutes them (D). With the effect (E) that takes place as a result of the dispute, such rational beliefs as "Being abandoned is not the end of the world, we broke up because we had issues; I can get along better with someone else." In line with these thoughts, functional feelings and behaviors (F) may occur such as hope and getting a new girlfriend. The fact that the individual develops rational beliefs and becomes capable of continuously using these beliefs thanks to therapy can be called Growth $(G)$.

In Oxford Dictionary (2017), growth is defined as "the process of developing physically, mentally, or spiritually." According to REBT growth can be defined as an individual's giving up using irrational beliefs in evaluating events and learning to use rational ones, and hence psychologically growing up and getting mature. In other words, the client learns REBT during psychological counseling; they can realize the irrational ways of their thought processes and how dysfunctional these are, they can develop and use rational beliefs instead of the irrational ones. When this process becomes consistent, one can say that the individual has grown. The events in the lives of these individuals are also influenced and shaped by this growth.

With growth $(G)$ the individual can approach new events $(A 2,3,4 \ldots)$ with a more rational viewpoint $(\mathrm{B})$, and when they evaluate the events with this viewpoint they can put forth functional emotions and behaviors. This process can be explained with the figure below, and the example is the fired individual: 
Şahin, E. S., \& Voltan Acar, N. (2019). Rational emotive behavior therapy from a new perspective. Journal of Human Sciences, 16(4), 894-906. doi:10.14687/jhs.v16i4.5821

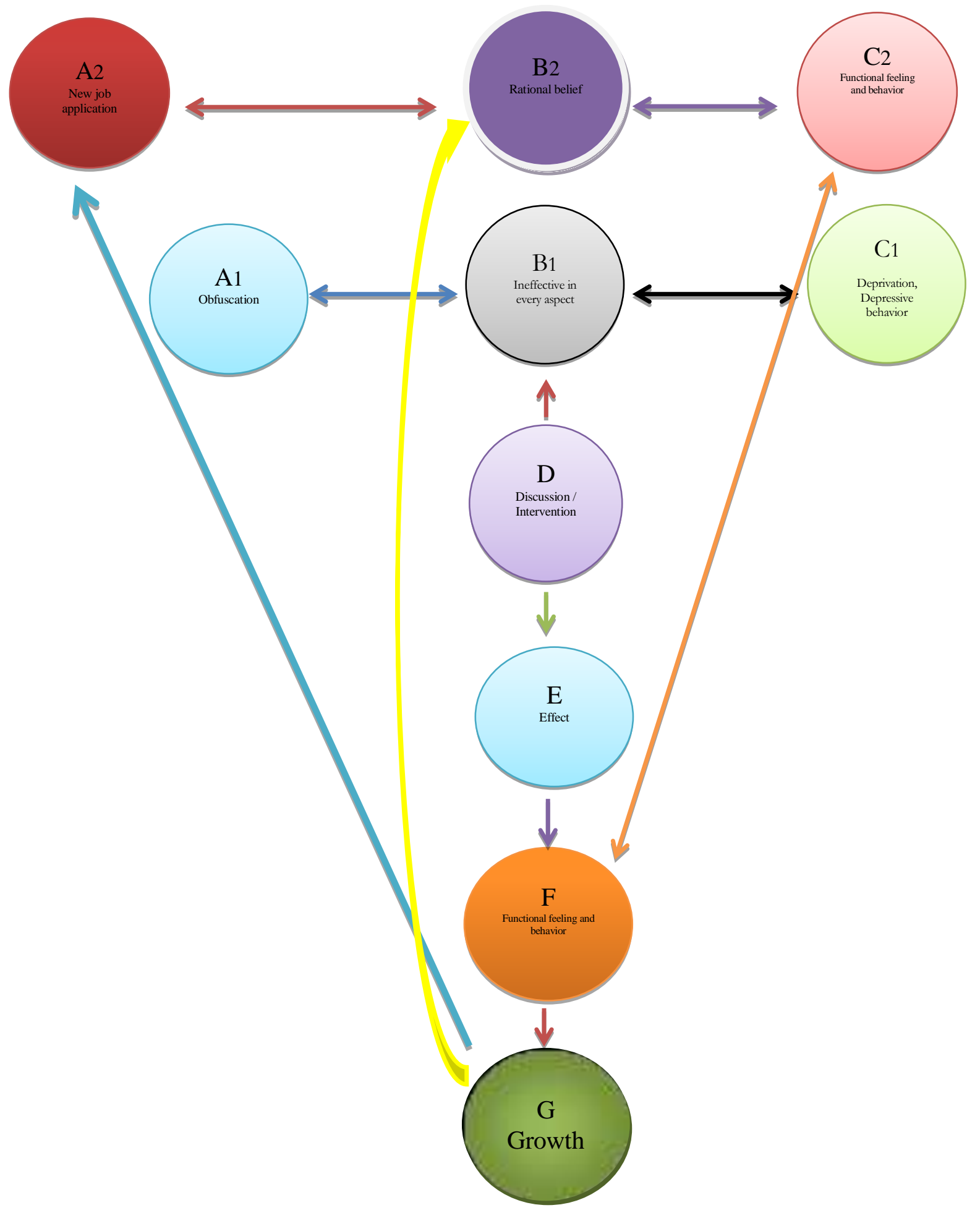

Figure 6. A new component in the A-B-C-D-E-F Process: G (Growth)

When Figure 6 is examined, it can be seen that $G$ is added as a new component to the AB-C-D-E-F process. As mentioned above, $G$ is growth. What Figure 6 shows is that, in a psychological counseling conducted with a rational emotive behavior approach the aim is the growth of the client and helping the client to look at new events (A2, 3, 4...) more rationally as a result of this growth. 


\section{Conclusion}

In a psychological counseling which applies a rational emotive behavior approach, the focus is on the emotion, thought, and behavior components of the client because the client does not have only one of these. He or she has emotion and thought as well as behavior. These components interact with one another, and each component contains elements of the others within themselves. The relationship between the components can affect what an individual thinks in a given situation, what emotions and behaviors he or she will exhibit. For instance, the individual perceives (B), an event (A) with the effect of the event, and may exhibit negative emotions and behaviors $(\mathrm{C})$ depending on this perception. However, this negative emotion and behavior does not end here, new events are also evaluated with the influence of these; and due to the evaluation negative emotions are behaviors occur again. In short, this process becomes a negative spiral and it constantly disturbs the individual.

In a psychological counseling which applies a rational emotive behavior approach, the aim is to break this negative spiral. Irrational beliefs (B) of the individual are refuted by disputing them (D). In the new case which came about with the effect (E) of this dispute, functional emotions and behaviors (F) occur. One of the aims in REBT-based psychological counseling is for the client to realize his or her irrational beliefs, distinguish them from rational ones, and to learn to overcome irrational beliefs.

The client learning this process and using rational beliefs in the face of new events can be called growth $(\mathrm{G})$. In this respect, the main aim of REBT-based psychological counseling can be said to be enabling growth.

The individual who has grown due to REBT-based psychological counseling can also achieve unconditional self-acceptance (USA) in addition to using rational beliefs in the face of new events, because he or she can overcome the feelings of self-worthlessness by evaluating themselves rationally. Moreover, the individual can try to reach long-term satisfaction seeing that pursuing short-term pleasures is not rational. In short, growth $(G)$ of the individual denotes both psychological maturation and having a sound psychological health. Thus, it can be argued that the aim of REBT-based psychological counseling is to provide growth.

\section{Declaration of Interest}

Authors declare no conflict of interest.

\section{Funding/Support}

We received no funding from any organization for this research.

\section{References}

Bernard, M. E. (2009). Dispute irrational beliefs and teach rational beliefs: an interview with Albert Ellis. Journal of Rational-Emotive \& Cognitive-Behavior Therapy, 27(1), 66- 76.

Bernard, M. E., Ellis, A., \& Terjersen, M. (2006). Rational emotive behavioral approaches to childhood disorders: History, theory, practice, and research. In M. Bernard \& A. Ellis (Eds.), Rational emotive behavioral approaches to childhood disorders: Theory, practice, \& research, 3-84. New York: Springer.

Clark, L. (2000). SOS Duygulara Yardm [SOS: Help for emotions: Managing anxiety, anger, and depression]. (Trans. G. Yazgan); İstanbul: Evrim Publishing.

Corey, G. (2008). Psikolojik dansma kuram ve uygulamalar [Theory and practice of counseling and psychotherapy]. (Trans. T. Ergene). Ankara: Mentis Publishing.

David, O. A., Matu, S. A., Pintea S., Cotet, C. D., \& Nagy, D. (2014). Cognitive-behavioral processes based on using the $\mathrm{ABC}$ analysis by trainees' for their personal development. Journal of RationalEmotive \& Cognitive- Behavior Therapy. 32, 198-215.

Dryden, W. (1990). Dealing with anger problems: Rational-emotive therapeutic interventions. Sarasota, FL: Professional Resource Exchange. 
Şahin, E. S., \& Voltan Acar, N. (2019). Rational emotive behavior therapy from a new perspective. Journal of Human Sciences, 16(4), 894-906. doi:10.14687/jhs.v16i4.5821

Dryden, W., \& Ellis, A. (2001). Rational Emotive Behaviour Therapy. In K. S. Dobson (Ed.), Cognitivebehavioral therapies. Newyork: Guilford, 295- 348.

Dryden, W., \& Neenan, M. (2006), Rational emotive therapy: 100 Keys points and techniques. Newyork: Routledge.

Ellis, A. (1962). Reason and emotion in psychotherapy. Oxford, England: Lyle Stuart.

Ellis, A. (1986). Rational emotive therapy applied to relationship therapy. Journal of Rational Emotive Therapy, 4, 4-21.

Ellis, A. (1987). The impossibility of achieving consistently good mental health. American Psychologist, 42, 364-375.

Ellis, A. (1973). Humanistic psychotherapy: The rational emotive approach. New York: Julian.

Ellis, A. (1977) Rational-emotive therapy: Research data that supports the clinical and personality hypotheses of RET and other modes of cognitive-behavior therapy. Counseling Psychologist, 7, 2-42.

Ellis, A. (1994). Reason and emotion in psychotherapy: Revised and updated. New York: Birch Lane Press.

Ellis, A. (1998). How rational emotive behavior therapy belongs in the constructivist camp. In M. F. Hoyt (Ed.), The handbook of constructive therapies: Innovative approaches from leading practitioners (83-99). San Francisco, CA, US: Jossey-Bass.

Ellis, A. (2000). Rational Emotive Behaviour Therapy. R. Nelson- Jones (Ed.). Six key approaches to counseling \& therapy. London: Continuum, 181-227.

Ellis, A. (2002). Overcoming resistance: A rational emotive behavior therapy integrated approach. Newyork: Springer.

Ellis, A. (2003). Discomfort anxiety: A new cognitive-behavioral construct. Journal of Rational-Emotive \& Cognitive-Behavior, 21, 193-202.

Ellis, A. (2004). Why rational emotive behavior therapy is the most comprehensive and effective form of behavior therapy. Journal of Rational-Emotive \& Cognitive-Behavior Therapy, 22(2), 85-92.

Ellis, A. (2008). Rational emotive behavior therapy. In K. Jordan (Ed.), The quick theory reference guide: A resource for expert and novice mental healt professionals. Hauppauge, NY: Nova Sience Publishers, 127-139.

Ellis, A. (2010). Overcoming destructive beliefs, feelings, and behaviors: New directions for rational emotive behavior therapy. Amherst, NY: Prometheus Books.

Gladding, S. T. (2013). Psikolojik damısma [Counseling: A comprehensive profession]. (Trans. Ed. N. Voltan Acar; Trans.T. Sarı). Ankara: Nobel Akademik Publishing.

Gençtanırım, D. \& Voltan- Acar, N. (2007). Rational-emotive behavior approach and Sezen Aksu's songs. Journal of Education \& Science, 32(143), 27-40.

Harrington, N. (2005). The frustration discomfort scale: Development and psychometric properties. Clinical Psychology \& Psychotherapy, 12, 374-387.

Murdock, N. L. (2013). Psikolojik damışma ve psikoterapi kuramlar [Theories of counseling and psychotherapy]. (Trans. Ed. F. Akkoyun; Trans. F. Akkoyun \& R. Arr). Ankara: Nobel Akademik Publishing.

Sharf, R. S. (2014). Psikoterapi ve psikolojik damışma kuramlar [Psychotherapy and counseling theories] (Çev. Ed. N. Voltan- Acar; Çev. A. Tunç). Ankara: Nobel Akademik Publishing.

Nelson- Jones, R. (2003). Damısma psikolojisi kuramlar [The theory and practice of counseling and therapy], (Trans. Ed. F. Akkoyun; Trans. F. Akkoyun, \& S. Doğan). Ankara: Nobel Akademik Publishing.

Popa, C., \& Bochis, L. (2012). The effects of a rational emotive behaviour education program on the sociometric status and interpersonal perception modification of 9-10 year old romanian pupils. Procedia - Social \& Behavioral Sciences. 46, 5792-5796.

Szentagotai, A., \& Kallay, E. (2006). The faster you move the longer you live - a test of rational emotive behavior therapy? Journal of Cognitive \& Behavioral Psychotherapies, 6(1), 69-80.

Oxford Dictionaries (2017). [online: https://en.oxforddictionaries.com/ date of access: May, 192017.

Türkçapar, M. H. (2011). BilisselTerapi [Cognitive therapy]. Ankara: HYP Publishing.

Zhaleh, N., Zarbakhsh, M. \& Faramarzi, M. (2014). Effectiveness of rational-emotive behavior therapy on the level of depression among female adolescents. Journal of Applied Environmental \& Biological Sciences, 4(4), 102-107. 